\title{
O INVISÍVEL DAS RELAÇÕES VISÍVEIS NA ESCOLA
}

\section{Maristela Marçal}

\section{RESUMO}

Considerando a importância da escola privilegiar as relações e interações estabelecidas entre todos os sujeitos da escola, nos seus diversos espaços e tempos, bem como a influencia destas relações na organização e funcionamento da unidade escolar, o presente artigo busca discutir sobre as influencias, ressonâncias e possibilidades que estas relações exercem nas ações dos professores como dos alunos no cotidiano da escola. Para tanto, tomo como espaço-tempo de discussão e reflexão sobre o assunto, três importantes situações que vivenciamos na EMEF Padre Francisco Silva: o Festival da Amizade, a Caminhada Cidadã e o Festival de Dança e Expressão Corporal.

\section{PALAVRAS-CHAVES}

Relações interpessoais; Relação professor-aluno; Movimento

\section{THE INTERPERSONAL RELATIONS IN THE SCHOOL}

\begin{abstract}
Considering the importance for the school to privilege the relations and interactions between all the subjects at the school, in its spaces and times, as well as the influence of these relations in the organization and functioning of the school unity, the present article intends to discuss about the influences, resonances and possibilities that these relations exercise in the actions of students and teachers at the school's quotidian. For such, I take as timespace of discussion and reflection about the question three important situation that we live at the "Padre Francisco Silva”: the Friendship Festival, the Citizen Walk and Corporal Expression.
\end{abstract}

\section{KEYWORDS}

Interpersonal relations; Teacher-student relation, Movement.

\section{INTRODUÇÃO}

Hoje estou assim...

Hoje estou assim, querendo ver e sentir uma escola que priorizasse este ser que está presente, sendo escola... Gente. Escola que é pura relação, interação, caminhos, processos de descobertas e tantas interrogações.

Quando observo a estrutura física das escolas em nada traduzem o espaço com pessoas. Queria que as paredes caíssem e pudéssemos aprender no gramado, embaixo das árvores e dali falássemos do tempo e espaço. Qual? Do tempo dos sentidos e sentimentos, dos movimentos, dos saberes expressados de variadas formas na pintura, na palavra, no som, no silêncio, apenas deixando o corpo falar.

É, hoje estou assim...

(C) ETD - Educação Temática Digital, Campinas SP, v.7 , n. esp., p.51-60 , jun. 2006 - ISSN: 1676-2592. 51 


\section{DIMENSÕES RELACIONAIS NA ESCOLA \\ Grupo de Pesquisa em Ensino Superior}

Que todos professores, durante uma aula, estivessem num grande encontro com seus parceiros alunos e compartilhassem a grande magia que é ensinar e aprender, conversar, escutar e refletir. E neste momento, todos estaríamos costurando uma bela colcha de conhecimentos, numa brincadeira artesanal, seríamos artesãos do conhecimento. Ao falar em física, química, matemática, a poesia destes saberes se apresentaria na descoberta das incógnitas, dos teoremas, de modo lúdico, explorando o pensar, os sentidos, a beleza e de repente a aula chamada ciências mostrasse o gosto que vem da química dos sabores, dos cheiros e uma outra prosa surgisse.

É, hoje estou assim...

A partir das nossas discussões a gente, o grupo Afeto que estuda a temática -relações interpessoais - foi redescobrindo que a escola é assim relações, interações, diferenças e indiferenças, num universo com variados dilemas e visões, espaços-tempos explorados e sonhos a serem conquistados.

É, hoje estou assim, pensando e escrevendo sobre a minha escola.

As certezas e as incertezas de uma realidade chamada escola “Pe.Francisco Silva”. Espaço escolar com suas histórias, trajetórias de sucessos e insucessos, de tantas relações entre pessoas que fizeram e fazem parte da dinâmica viva do cotidiano educacional, estabelecidas pelas interações.

A escola encontrava-se passando por processos de mudanças, principalmente nas relações intra e inter pessoais, já que o grupo de gestão e de professores havia mudado em decorrência da efetivação nas funções de direção, vice-direção e orientação pedagógica, além da remoção e substituição de professores. Foi significativa a passagem de algumas destas pessoas, que tiveram um vínculo de envolvimento, de identificação com a dinâmica e com o pessoal da escola, ocasionando uma reestruturação pessoal e profissional a nós todos. Como exemplo, a alteração no grupo de gestão que reconheceu e estruturou-se nas melhores possibilidades e soluções do trabalho educacional (pedagógico, administrativo, organizacional) conjuntamente à comunidade escolar e vice-versa, trajetória acompanhada de ações, no conhecimento de seus parceiros, na superação dos conflitos, nos acertos e erros e em ajustes necessários, ainda mais quando se trata das relações com muitos sujeitos.

Justamente neste quadro de mudanças iniciava-se uma proposta de grupo de estudo em parceria com a universidade, ampliando os nossos vínculos, buscando outros protagonista, professorespesquisadores, estagiários vindos da universidade, para participarem do universo da escola "Padre Silva”.

Estabeleceu-se um grupo de estudo em 2003, num momento em que a escola no aspecto dos relacionamentos (professores, alunos, gestão) encontrava-se com alguns conflitos, principalmente, no 


\section{DIMENSÕES RELACIONAIS NA ESCOLA Grupo de Pesquisa em Ensino Superior}

diálogo e comunicação e nas questões disciplinares, ocasionando expectativas e ansiedades nos profissionais da unidade, em certos instantes a desmotivação. E foi a estruturação de mais um espaço para o encontro e trocas de experiências das nossas tantas incertezas que nos deu auxílio e suporte necessários ao fortalecimento dos vínculos existentes e de outros que viriam.

Em 2004, novos parceiros integraram-se ao grupo de estudo, um projeto mais amplo, nos trouxe a oportunidade de pensamento e ação sobre nossa realidade, as expectativas anteriores foram atenuadas. A constituição do novo grupo foi um processo de aproximação, sedução e confiança, a conquista do espaço de um trabalho em equipe, os coordenadores do grupo com suas orientações aos nossos dilemas pedagógicos, nos esclarecimentos de temas estudados como a indisciplina, a avaliação, os processos de aprendizagem, a motivação, refletidos e discutidos com diferentes visões, foram parceiros que incentivaram a prática profissional, pensada numa perspectiva de mudança e diálogo. Comunicação que não ficou restrita ao nosso espaço-escola, a motivação em compartilhar as experiências educacionais em outros espaços, em eventos como no II Seminário Fala Outra Escola, da Faculdade de Educação da Unicamp (2004), palestra a alunos de licenciatura da universidade. Isto tudo vindo do incentivo que não se restringiu num fazer, mas no fazer impulsionado pelo respeito acolhedor.

Encontro-me aqui, também, personagem num caminhar, adequando-se a estas tantas alterações. Nós que somos os sujeitos, os alunos, os pais, os funcionários, os professores, a equipe de gestão, exalunos, ex-funcionários, a comunidade escolar fazendo o espaço ter vida, nas relações de encontros, desencontros, idas e vindas alteradas anualmente, modificações necessárias que deixam suas marcas. São as marcas das vivências e vínculos pessoais que nos enriquecem em nossa formação e constituição do que somos, nossa imagem, a auto-estima, nossos valores éticos e morais, enfim em nosso corpo e na alma. Isto se estabelece com a identificação com o outro, na afetividade, na amizade me reconhecendo pertencente a um espaço no e para o grupo, conseqüentemente, podendo ocorrer, a admiração, o respeito, a reciprocidade, os enfrentamentos, os conflitos, a busca pelo entendimento frente às diferenças, pois, vivemos em uma sociedade em constante transformação, dinâmica, rica em contrastes e contrários que se desenvolve e muda.

“A consciência psicológica ou o eu é formada por nossas vivências, isto é, pela maneira como sentimos e compreendemos o que passa em nosso mundo que nos rodeia, assim como o que se passa em nosso interior” (Chauí, 2000, p.71).

Entendo que a escola oportuniza muitos espaços e tempos para conhecê-la e reconhecê-la em seus contrastes, em movimento de grupo ao não isolamento, a possibilidade de sentir o espaço-escola em seu dinamismo, que não é o que os olhos detectam imediatamente, mas aquilo que se vê e se sente 


\section{DIMENSÕES RELACIONAIS NA ESCOLA Grupo de Pesquisa em Ensino Superior}

no percebido num ritmo vindo do sensível, do coração. Relacionamentos de proximidade entre pessoas que podem oferecer ocasiões de descobertas, as surpresas, proporcionando transformações qualitativas em nós e no outro, onde novos fatos e momentos escolares ocorram destas interações. Fatos escolares que não se encontram somente nas salas de aula, em reuniões, numa armadura burocrática, miram-se nos movimentos das pessoas, agentes, nas atividades extra-sala, nos festivais, festas, torneios, organização de eventos, na partilha das experiências e conhecimentos. Dentre as várias propostas de trabalho pedagógico, das aulas e projetos relatarei três em que pude participar diretamente, entendendo serem atividades que nos proporcionaram vivências significativas no envolvimento entre pessoas, principalmente com nossos alunos. São: I) Festival da Amizade, II)Caminhada Cidadã, III) Festival Projeto Movimentarte- Dança e Expressão corporal.

\section{FESTIVAL DA AMIZADE}

Dinâmica anual com alunos de $4^{\mathrm{a}}$ à $8^{\mathrm{a}}$ séries (em 2004 feita com $1^{\mathrm{a}}$ a $8^{\mathrm{a}}$ séries) realizada há mais de dez anos na escola. São desenvolvidas atividades diversificadas orientadas numa proposta que visa os valores sócio-afetivos, cognitivos e culturais envolvendo todas áreas curriculares, enfatizando-se as diferentes formas de expressão e linguagens nas artes, no esporte e recreação, conhecimentos gerais, ocorrem em 4 dias. As equipes são constituídas por um número de alunos (varia ano/ano) de todas as séries, os alunos não participantes em equipes atuam em torcidas, cooperando com algum grupo. Há coordenação de dois líderes responsáveis pela organização e condução das equipes antes, durante as atividades que são elaboradas por uma comissão de professores, gestão e funcionários que em conjunto coordenam a realização do evento, com a participação também da comunidade.

O evento, em si, ocorreu de modo positivo, apresentando momentos significativos, mas aberto às reformulações no que se refere aos pontos desfavoráveis, detectados na avaliação entre os professores e funcionários e, os professores coordenadores com os alunos líderes. A partir da vivência de um fato escolar pudemos observar vários aspectos relacionados à dimensão das interações, resgato as avaliações da comissão organizadora e dos alunos líderes que trouxeram algumas colocações dos colegas do próprio grupo sobre o Festival. Partindo-se de três aspectos (que utilizaremos também em proposta para 2005 com as assembléias de classe) - 1ª) Eu elogio; 2a) Eu critico; e $3^{a}$ ) Eu sugiro.

Eu elogio sobre a comissão: A disponibilidade da programação das atividades que necessitavam de tempo prévio para serem elaboradas (teatro, danças, dramatizações),-elaboração das atividades lúdicas pelas equipes para as crianças menores, - menor $\mathrm{n}^{\circ}$ de atividades ao dia, -mudança no quadro de pontuação (premiação todos os dias), - integração e negociação entre as equipes, - provas 


\section{DIMENSÕES RELACIONAIS NA ESCOLA \\ Grupo de Pesquisa em Ensino Superior}

fraternas (Campanha do agasalho, do leite),-articulação entre os aluno-aluno, aluno-professor nos momentos de conflitos, -encontro a festa com todas equipes com bolo feito pelas mães e professora, as várias demonstração solidárias entre os alunos, - auxílio dos alunos com a comissão na resolução de conflitos e problemas.

Eu elogio sobre as equipes: encontro e integração dos grupos, união das equipes dentro dos grupos e entre os grupos, o trabalho da comissão de organização, atividades propostas, medalhas de destaque para alunos que ao final do evento tiveram um reconhecimento de todas as equipes pela sua ação cooperativa e participativa no Festival, festa final confraternização. A avaliação na perspectiva dos líderes: responsabilidade com os integrantes do grupo que dá trabalho, experiência de liderança, necessidade de trabalho conjunto entre os líderes, líder ser paciente, o líder leva culpa pelo erro, integração com alunos de $1^{\mathrm{a}}$ a $3^{\mathrm{a}}$ séries.

$\boldsymbol{E} \boldsymbol{u}$ critico sobre a comissão:- professores que não sabiam das atividades do festival, provas esportivas longas, dificuldades para obter pessoal que auxiliassem nos jogos, no teatro dificuldade estrutural e de som no local da apresentação , curto tempo para organizar as atividades ocasionando um desgaste desnecessário a comissão .

$\boldsymbol{E} \boldsymbol{u}$ critico sobre as equipes: pouco tempo de entrega das provas, arbitragem do jogo Base, reunir os integrantes para organizar as atividades, o descompromisso de alguns elementos do grupo, hostilização em alguns momentos com árbitros dos jogos e comissão julgadora.

Eu sugiro sobre a comissão: organização com um mês de antecedência (Planejamento), acompanhar os líderes com professores orientadores fazendo-se um rodízio pelas equipes durante as atividades, comissão com mais autonomia para decisões e horários para reuniões, distribuição de funções com antecedência entre professores envolvidos na equipe da escola, normalmente sempre os mesmos, aumentar mais um dia de Festival, local na escola para as equipes se reunirem (acompanhamento na elaboração,organização dos grupos), elaborar uma forma de convite que motive a participação da comunidade, atividades que envolvam mais as crianças com necessidades especiais.

Eu sugiro sobre as equipes: Tarefas entregues com mais antecedência, voltar o jogo de xadrez, mesma música para os grupos na dramatização, local na escola para reunião, outro Festival em outubro.

\section{Comentários de alguns alunos líderes:}

(C) ETD - Educação Temática Digital, Campinas SP, v.7 , n. esp., p.51-60 , jun. 2006 - ISSN: 1676-2592. 55 


\section{DIMENSÕES RELACIONAIS NA ESCOLA Grupo de Pesquisa em Ensino Superior}

Giuliane: A liderança criou em mim mais responsabilidade, dá trabalho.

Thiago: Gostei da medalha de honra.

Rodrigo e Mariana: Duas equipes xingaram a comissão eu não gostei. Gostaram da experiência de liderar uma equipe, mesmo com desfalque mantiveram-se nas funções em respeito aos participantes, principalmente os menores.

Leandro: lembrou da necessidade do trabalho conjunto entre os líderes. E como é ruim marcar reunião e o colega não comparecer.

Jéssica: Para ser líder necessita de paciência.

Participando da comissão organizadora pudemos acompanhar o processo de realização de uma situação escolar em que se percebe os desdobramentos inter e intra- pessoais dos profissionais da escola, dos alunos e dos pais. Há exigência na disponibilidade de tempo na realização de um trabalho com o outro, em reuniões, nas atividades em si.Tivemos na época que articular e negociar alguns conflitos com a gestão da escola para a realização de reuniões de planejamento das atividades do festival, posicionamento na tomada de decisão, a iniciativa de participação dos colegas professores no envolvimento e colaboração com as atividades. Exigindo de todos a paciência, a tolerância, o respeito e acima de tudo o entendimento já que todos, apesar das diferenças, tínhamos um objetivo em comum, a realização do Festival.

As reuniões da comissão com os alunos líderes foram outro espaço/meio escolar de participação dos alunos-sujeitos participantes com as professoras, avaliando um projeto da escola organizado por ambos. Encontros que ocorreram antes para orientação das tarefas e durante na administração dos problemas e busca de soluções e ao final com a avaliação do que fizemos juntos, também na confraternização festiva. Os garotos demonstraram em seus papéis de coordenadores maturidade, coerência de idéias e posicionamentos, criticidade. Eu e a professora Edna S. Klein (Prof ${ }^{a}$ de Ciências) que estamos há um maior tempo na escola acompanhamos alguns destes alunos pudemos observar, por exemplo, em alguns deles que a timidez, as ações de rebeldia em anos anteriores, apresentavam-se de modo diferentes, apropriando-se de um momento escolar no exercício de convivência. Percebemos a escola auxiliando no do processo de crescimento e desenvolvimento individual as mudanças. Embora com todas as dificuldades enfrentadas na organização, ao final estava

(C) ETD - Educação Temática Digital, Campinas SP, v.7 , n. esp., p.51-60 , jun. 2006 - ISSN: 1676-2592. 56 


\section{DIMENSÕES RELACIONAIS NA ESCOLA \\ Grupo de Pesquisa em Ensino Superior}

inscrito nas falas, nas palavras, nos gestos dos alunos a alegria de estar no espaço escola com uma atividade de significado para eles, agindo, responsabilizando-se, cooperando. Fazendo e sendo escola.

\section{CAMINHADA CIDADÃ}

A Caminhada Cidadã foi um outro espaço-tempo escolar que pode favorecer o exercício de relações, ocorrida nas ruas próxima à escola, com o objetivo de envolver a comunidade e a escola, integradas numa atividade conjunta, apresentando a proposta pedagógica: Cidadania-Respeito, Cooperação e Participação e os eixos norteadores- Eu e o outro, Eu e o grupo, Eu e o Mundo e os projetos. Houve a participação de outras unidades escolares, organizações-não-governamentais (ONGs), grupos de danças que foram integrando-se a caminhada durante o percurso com outras fanfarras, performances circenses e acrobáticas, danças e os pais, promovendo assim, o encontro comunidade e escola.

A escola de $1^{\mathrm{a}}$ a $8^{\mathrm{a}}$ séries mostrando o seu trabalho educacional de diferentes formas, modos de expressões e uso de recursos materiais, mas o principal o humano. Estava lá, a GENTE na rua-escola, com cartazes, fantasias, alegorias, manifestações corporais cantando, brincando. É interessante resgatar, além da caminhada em si, o processo de preparo de um evento no fazer motivado, construído, participado, onde se direcionam os interesses, as capacidades, as habilidades dos alunos e professores, seja, por exemplo, na constituição de um plano de ação, na elaboração de um painel, na articulação de professores na realização de tarefas em conjunto, nas ações e transferências de conhecimentos, solução de problemas. Entendo serem estes e outros momentos na escola, além da relação da sala, que oferecem aproximação entre as pessoas, onde podemos reconhecer os alunos e nos reconhecer, muitas vezes em idéias e atitudes que promovam os bons acontecimentos imprevistos e não planejados, rompendo com rotina do previsível e o ritmo sistemático escolar. Colocou-se a escola em movimento numa ação em comunidade articulando com outros, novos vínculos, no encontro, entrelaçados na troca social, finalizando o trajeto na praça de esporte do bairro.

\section{FESTIVAL DE DANÇA E EXPRESSÃO CORPORAL}

O Projeto Dança/expressão corporal (Movimentarte) é mais um momento escolar com alunos de $1^{\mathrm{a}}$ à $8^{\mathrm{a}}$ séries, sob com a orientação das professoras Gisele F. Gomes (História e Dança) e Maristela Marçal (Ed. Física e Pedagogia). A proposta tinha como objetivo uma vivência integrada à comunicação da linguagem corporal do movimento, na expressividade, ludicidade, na descoberta e (c) ETD - Educação Temática Digital, Campinas SP, v.7 , n. esp., p.51-60 , jun. 2006 - ISSN: 1676-2592. 


\section{DIMENSÕES RELACIONAIS NA ESCOLA Grupo de Pesquisa em Ensino Superior}

recriação das possibilidades do dançar, com aulas semanais que tinham a duração de 50 minutos, 4 turmas $\left(1^{\mathrm{a}} / 2^{\mathrm{a}}, 3^{\mathrm{a}} / 4^{\mathrm{a}} / 5^{\mathrm{a}}, 6^{\mathrm{a}}, 7^{\mathrm{a}} / 8^{\mathrm{a}}\right.$ séries). Este projeto iniciou-se da observação das professoras e da necessidade dos alunos de aumentarem as suas possibilidades corporais, fato que já vinha ocorrendo nas aulas de educação física, mas que poderiam ser ampliadas abordando a exploração espacial, o ritmo, o tempo, as diferentes linguagens do corpo e o significado do trabalho da percepção individual e do outro na atividade coletiva do movimento humano.

Nós, professoras, tínhamos formações e experiências diferenciadas, mas também ponto de vista e crenças comuns. A estruturação do projeto no planejamento, objetivo e estratégia foram se constituindo a partir do respeito mútuo do espaço e tempo de cada uma das professoras envolvidas, a confiança, a admiração e afetividade proporcionou um vínculo de grande parceria de trabalho de uma com a outra. Fortalecendo e modificando os nossos conhecimentos individuais que integrados reestruturaram-se na construção de uma proposta com a expressão corporal e dança, aliado também aos conhecimentos dos alunos. Todo o processo direcionou-se aos alunos numa relação que buscava mostrá-los um conhecimento novo, não acabado, mas recriado. Para eles, o novo aparecia, o medo, a exposição ao desconhecido, ainda que houvesse a espera da transmissão de movimentos padronizados, coreografias prontas, contrário ao que objetivávamos. Durante vários momentos das aulas fizemos avaliações com alunos do caminho percorrido e com a criticidade nos questionavam a respeito de alguma atividade, davam idéias, já estávamos em estado de parcerias e trocas.

Na dinâmica das aulas, as turmas tinham diferentes ações e participações, fomos estruturando o projeto e os vínculos de identidade conosco, com os colegas e a proposta firmavam-se no afeto, na confiança e respeito, pois, acreditavámos em nossas ações e também nos responsabilizávamos pelo grupo.Todo o processo resultou em um Festival de Dança, através da expressividade corporal viajamos na história da dança e da música, com diversidade nas ações corporais, estilos musicais, textos poéticos, a arte em movimento, trouxemos outros conhecimentos, relacionamentos com o envolvimento dos alunos que se apropriaram do projeto. A participação na produção do evento, na agilização de ensaios, na elaboração de coreografias, confecção de adereços, painéis, preparo do local do evento um outro ambiente (Sociedade de Bairro). Já não eram os mesmos alunos do início do ano, nem nós, as mesmas professoras.

(c) ETD - Educação Temática Digital, Campinas SP, v.7 , n. esp., p.51-60 , jun. 2006 - ISSN: 1676-2592. 58 


\section{CONSIDERAÇÕES FINAIS}

Considerando todas as questões relacionadas à função da escola na formação bio-psico-social e cultural dos indivíduos, entendo que ela deva privilegiar o papel social espaço-tempo de viver as relações e interações, estimuladas em seu funcionamento, organização, currículos do conhecimento e percepção de quem e como somos, relação com o outro e o meio ambiente vivenciado.

Entendo que estes fatos e momentos escolares possibilitaram desenvolvimento do indivíduo numa dimensão mais humana, considerando alguns aspectos: -atividades significativas pensadas e elaboradas para os alunos, -a identificação e participação com as propostas, -o aprendizado cognitivo e afetivo, -espaços escolares como ambiente de conhecimentos, -interações entre pessoas mediadoras de informação, -modos diferentes de como ensinar nos projetos,estratégias diferentes, -integração da família- comunidade-escola.

E a escola transcorre tão viva num grande palco com entradas e saídas com vários protagonistas. De que modo estes fatos, ações, atitudes, posicionamentos são analisados e vistos pela comunidade escolar, onde muitas vezes perdemos o bonde de um momento, deixando passar algumas oportunidades de viver estes vínculos. Na proposta pedagógica escolar que preconiza a cooperação, a autonomia, trabalho solidário, respeito, dentre outros, nos parece tão claro, mas será que na perspectiva da prática exercitada, estes aspectos são realmente considerados ou ainda nos é de difícil e intrincada aplicação. Buscar no invisível, nos detalhes das relações visíveis, um outro olhar de ser e fazer escola. No entanto algumas indagações me surgem.Qual o aproveitamento de espaços e tempos no aprendizado? Quais são os tempos internos ou externos que se processam vínculos entre pessoas? Em quais espaços estabelecem-se as parcerias de solidariedade, cooperação? E os estabelecimentos de afinidades (ou não)? Qual a minha capacidade e sua de tolerância ? Qual é o seu e o meu envolvimento? As incertezas? Os medos? A exposição individual? O desgaste? O poder? A hierarquia? O contexto? Os interesses individuais? A coletividade? A motivação? A felicidade?

Respostas?????

Ao vivenciar os momentos e fatos escolares senti, aos senti-los, percebi, desestruturei as minhas “certezas” e muitas “incertezas”, envolvendo-me, aprendendo e mudando. Num envolvimento com compromisso que estimula e desafia, em convivências que também buscam o novo, o experimento, 


\section{DIMENSÕES RELACIONAIS NA ESCOLA Grupo de Pesquisa em Ensino Superior}

vínculos passados e presentes que ao deixarem seus registros nos transformam,complementam, direcionando a um trabalho com muito mais prazer e alegria, é conquista.

Como disse anteriormente, é um percurso cujo caminho apresenta diversos momentos e direções, o tempo encarrega-se de amadurecê-los. Há ligações que se rompem, mas que influenciam o nosso fazer, que não se apaga, são as marcas significativas que se internalizam processando-se de modo variado, é um presente para o nosso desenvolvimento. Já existem aqueles que ainda não se encontraram na mesma trajetória, ou estão por outros caminhos. É o tempo individualizado, particularizado, que também deve ser compreendido. A percepção e o aprendizado vivido das relações entre pessoas que podem nos conduzir a ações mais tolerantes, pacientes e carinhosas em relação ao outro.

Ao relatar as experiências das relações inter e intra-pessoais, busco desenvolver o trabalho com referências teóricas que dão o suporte necessário a nossa prática docente, num assunto que nos é muito próximo que continuarei a estudar. Foram indagações desta realidade Escola "Padre Silva”, mas mantenho a motivação amparada nas referências construídas pelas interações no e com nosso espaço mundo e o outro, e outros virão, em cada tempo e espaço. São os passos de uma caminhada. Já não somos os mesmos professores de ontem. Somos professores de hoje e continuaremos buscando um amanhã melhor.

\section{REFERENCIAS}

CHAUÍ, M. Filosofia. São Paulo: Editora Ática, 2000.

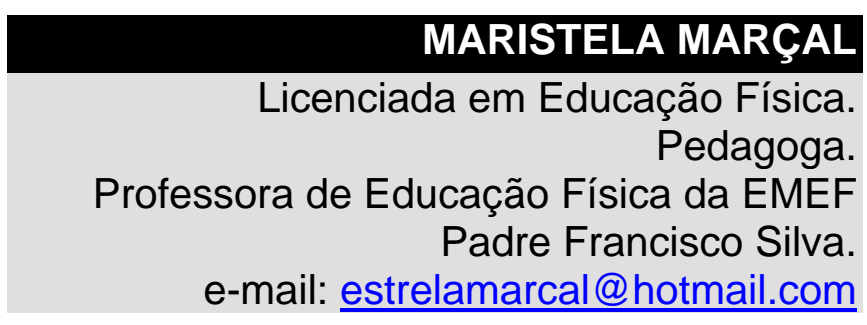

ARTIGO RECEBIDO EM: 10/01/2006-05 Aceito para publicação em: 09/05/2006 